\title{
Synthesis of Some New Azetidinone Derivatives Containing Aryl Sulfonyloxy Group
}

\author{
H.S. PATEL* and H.D. DESAI \\ Department of Chemistry, S. P. University, \\ Vallabh Vidyanagar - 388120. \\ Gujarat (INDIA)
}

Received 23 April 2004; Accepted 9 June 2004

\begin{abstract}
Some novel azetidinone derivatives containing aryl sulfonyloxy group have been prepared. The 4-sulfonyloxy aniline derivative (2) has been prepared by reaction of 4-nitro phenol (sodium salt) with $\mathrm{N}$-acetyl sulfanilyl chloride (ASC) followed by hydrolysis by ethanolic $\mathrm{HC}$. This compound (2) undergoes facile condensation reaction with aromatic aldehydes to yield different Schiff's bases (3a-h). Cyclocondensation of compounds (3a-h) with chloro acetyl chloride yields different 2-azetidinone derivatives (4a-h).
\end{abstract}

Key words : New Azetidinone Derivatives, Aryl Sulfonyloxy

\section{Introduction}

2-Azetidines have been extensively investigated by the organic chemists due to their close association with various types of biological activities. ${ }^{1-4}$ Azetidine-2-ones also have great importance because of the use of $\beta$-lactam derivatives as an antibacterial agents. ${ }^{5}$ The antibiotic activity is closely related to the substituted $\beta$-lactam ring structure. ${ }^{6}$ More particularly and recently these types of compounds have been found in the treatment of T.B. and other chemotherapeutic diseases. ${ }^{7}$ The area in which this type of compound containing arylsulfonyloxy group $\left(\mathrm{ArSO}_{3}\right)$ has not received attention in spite of well defined antibacterial activity of sulfonyl group. ${ }^{8}$

Hence it was thought interesting to synthesize novel azetidinone derivatives containing aryl $-\mathrm{SO}_{3}$ group. The present paper comprises the synthesis and characterization of azetidinone derivatives as shown in Scheme - 1. 

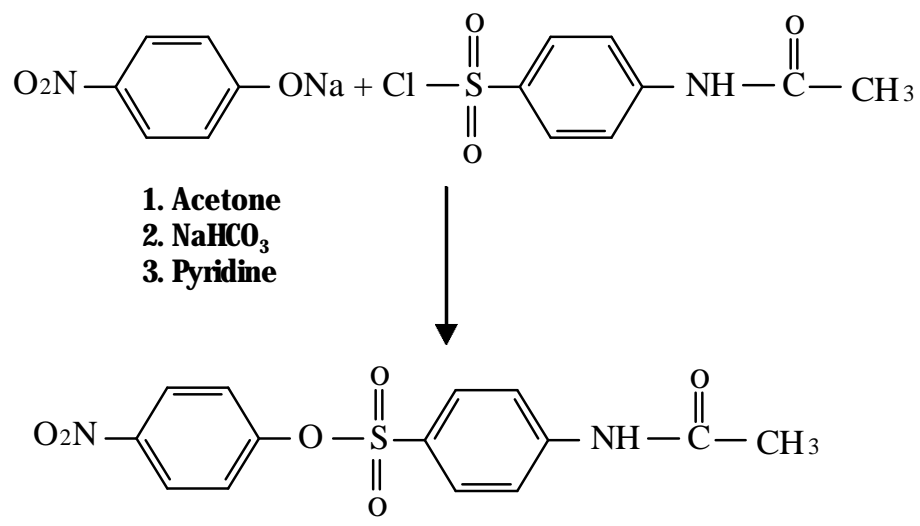

Hydrolysis $\mathrm{EtOH} / \mathrm{HC}$<smiles>Nc1ccc(S(=O)(=O)Oc2ccc([N+](=O)[O-])cc2)cc1</smiles>
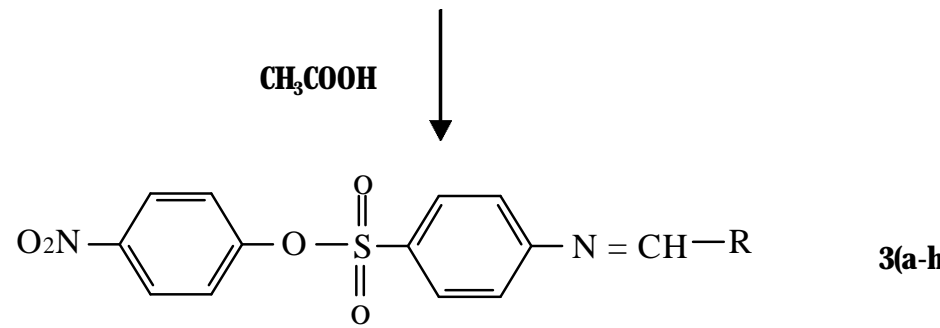<smiles>[R]C1([2H])C(Cl)C(=O)N1c1ccc(S(=O)(=O)Oc2ccc([N+](=O)[O-])cc2)cc1</smiles>

Where, $\mathrm{R}=\mathrm{a}$-Benzaldehyde, $\mathrm{b}$-4-Methyl benzaldehyde, c- 4-Methoxy benzaldehyde, d- 4-Chloro benzaldehyde, e- 4- Nitro benzaldehyde, f- 4-Hydroxy benzaldehyde, g- 3,4- Dimethoxy benzaldehyde, h- 3-Methoxy-4-hydroxy benzaldehyde 


\section{Experimental}

Melting point was taken in open capillary tubes and are uncorrected. The synthesized compounds were characterized by IR spectroscopy, thin layer chromatography and elemental analyses of $\mathrm{C}, \mathrm{H}$, and $\mathrm{N}$. The IR spectra were recorded in $\mathrm{KBr}$ pellets on a Nicolet 400D spectrometer and ${ }^{1} \mathrm{H}$ NMR spectra in $\mathrm{CDC}_{3} / \mathrm{DMSO}$ on Hitachi R-1500, $60 \mathrm{MHz}$ spectrometer using TMS as a internal standard. TLC was performed on silica gel layer and spots were visualized by exposing the developed spots and dry plates to $\mathrm{I}_{2}$ vapours. The required 4-acetamide benzene sulfonyl chlorides was prepared by reported method. ${ }^{9}$ All chemicals used were of laboratory grade.

\section{Preparation of 4-(4'-nitrophenyl sulfonyloxy) acetanilide (1)}

Typical procedure

Sodium salt of 4-nitro phenol ( 0.05 mole) was dissolved in mixture of $40 \mathrm{ml}$ anhydrous acetone and $1 \mathrm{ml}$ of dry pyridine in $250 \mathrm{ml} \mathrm{R.B.} \mathrm{flask} \mathrm{and} 11.67 \mathrm{gm}$ ( 0.05 mole) of pure 4-acetamido benzene sulfonyl chloride (ASC) was added portion wise with stirring. Sodium bicarbonate ( 0.05 mole) was added as an acid acceptor. The reaction mixture is set aside overnight and almost pure 4-(4'nitro phenyl sulfonyloxy) acetanilide is filtered off and washed with cold water and air-dried. It was then recrystalized from ethanol to give whitish yellow product in $60-70 \%$ yield. Melting point of the compound (1) was found to be $190^{\circ} \mathrm{C}$.

Preparation of 4-(4-nitro phenyl sulfonyloxy) aniline (2) by hydrolysis of (1)

Typical procedure

The compound (1) was hydrolyzed by refluxing with $75 \mathrm{ml}$ of ethanol containing $15 \mathrm{ml}$ of conc. HQ for 4-5 hrs. It was then poured into ice-cold water and finally made just alkaline with liq. ammonia. The resultant hydrolyzed product (2) is filtered off and washed with water and dried. It was then recrystalized from ethanol to give product in $65-75 \%$ yield. Melting point of the compound (2) was found to be $105^{\circ} \mathrm{C}$.

\section{Preparation of schiff's bases (3a-h)}

Typical procedure : A mixture of equimolar amount of hydrolysis product (2) (0.01mole) and different aromatic aldehydes $(0.01 \mathrm{~mole})$ in $50 \mathrm{ml}$ acetic acid was refluxed for about $10 \mathrm{hrs}$ on oil bath. The reaction mixture was cooled and it was poured into ice water and the solid obtained was filtered and recrystalized from ethanol to give yellow ish white products (3a-h) in $50-55 \%$ yield.

Preparation of Azetidinone derivatives (4a-h).

Typical procedure : A mixture of different schiff's bases (3a-h) $(0.002$ mole) and triethylamine (TEA) (0.004 mole) was dissolved in 1,4-dioxane $(50 \mathrm{ml})$ and cooled and stirred. To this well stirred cooled solution chloro acetyl chloride ( 0.004 mole) was added drop wise within a period of 20 minute. The reaction mixture was then stirred for further $3 \mathrm{hrs}$ and then refluxed for $8 \mathrm{hrs}$. The resultant mixture was concentrated, cooled, then poured into ice-cold water and then extracted with ethyl acetate. The solvent was evaporated and the product thus obtained was purified by column chromatography over silica gel using $15 \%$ ethyl acetate: $85 \%$ benzene as eluent. Recrystallization from ether/ $n$-hexane yields Azetidinone derivatives (4a-h) in $50-55 \%$ yield.

\section{Result and Discussion}

The synthesis of Azetidinone derivatives is accomplished as shown in the Scheme -1. Analytical and spectral data are given in Table -1 .

It was observed that $\mathrm{N}$-acetyl sulfanilyl chloride on reaction with sodium salt of 4-nitrophenol give 4-(4'nitro phenyl sulfonyloxy) acetanilide (1). Its structure was established on the basis of their elemental analysis and IR spectra showing bands at $1210-1150 \mathrm{~cm}^{-1}\left(\mathrm{SO}_{3}\right)$ and $1550 \mathrm{~cm}^{-1}(\mathrm{CONH})$. Compound (1) was easily hydrolyzed ${ }^{10}$ with $\mathrm{EtOH} / \mathrm{HQ}$ to give compound (2). The hydrolyzed product (2) have consistent value of C.H.N and S contents with predicated structure. Also compound (2) shows the diazo test for primary amine $\left(-\mathrm{NH}_{2}\right)$ group. The IR spectra of (2) show absorption bands at $3390 \& 3410$ $\mathrm{cm}^{-1}\left(\mathrm{NH}_{2}\right)$ and $1210-1150 \mathrm{~cm}^{-1}\left(-\mathrm{SO}_{3}\right)$. The compound (2) was also confirmed by ${ }^{1} \mathrm{HNMR}$ spectra show ing peaks of $\mathrm{NH}_{2}$ at 4.20 and 7.2-8.3 for aromatic protons. 
Table - 1 Analytical and Spectral data of Compounds (4a-h)

\begin{tabular}{|c|c|c|c|c|c|c|c|}
\hline \multirow{2}{*}{ Comps } & \multirow{2}{*}{$\begin{array}{l}\text { Molecular } \\
\text { formula }\end{array}$} & \multicolumn{3}{|c|}{$\begin{array}{l}\% \text { Analysis Calculated } \\
\text { (Found) }\end{array}$} & \multirow{2}{*}{$\begin{array}{c}\text { Yield } \\
\%\end{array}$} & \multirow{2}{*}{$\begin{array}{l}\text { M.P. } \\
{ }^{0} \mathrm{C}\end{array}$} & \multirow[t]{2}{*}{ PMR $(\delta, p p m)$} \\
\hline & & $\% \mathrm{C}$ & $\% \mathrm{H}$ & $\% \mathrm{~N}$ & & & \\
\hline $4 a$ & $\mathrm{C}_{21} \mathrm{H}_{15} \mathrm{O}_{6} \mathrm{~N}_{2} \mathrm{SC}$ & $\begin{array}{l}54.96 \\
(54.85)\end{array}$ & $\begin{array}{l}3.20 \\
(3.10)\end{array}$ & $\begin{array}{l}6.10 \\
(6.05)\end{array}$ & 50 & 140 & $\begin{array}{l}\text { 4.6-4.8 }\left(1 \mathrm{H}, \mathrm{d}, \mathrm{C}_{4} \mathrm{H}\right), \\
5.2-5.3\left(1 \mathrm{H}, \mathrm{d}, \mathrm{C}_{3} \mathrm{H}\right), \\
7.2-8.3(13 \mathrm{H}, \mathrm{m}, \text { aromatic }) \\
1.9\left(3 \mathrm{H}, \mathrm{s}, \mathrm{CH} \mathrm{H}_{3}\right)\end{array}$ \\
\hline $4 b$ & $\mathrm{C}_{22} \mathrm{H}_{17} \mathrm{O}_{6} \mathrm{~N}_{2} \mathrm{SC}$ & $\begin{array}{l}55.87 \\
(55.75)\end{array}$ & $\begin{array}{c}3.59 \\
(3.50)\end{array}$ & $\begin{array}{l}5.92 \\
(5.80)\end{array}$ & 52 & 175 & $\begin{array}{l}\text { 4.6-4.8 }\left(1 \mathrm{H}, \mathrm{d}, \mathrm{C}_{4} \mathrm{H}\right), \\
\text { 5.3-5.4 }\left(1 \mathrm{H}, \mathrm{d}, \mathrm{C}_{3} \mathrm{H}\right), \\
\text { 7.3-8.5 } \\
2.9\left(3 \mathrm{H}, \mathrm{H}, \mathrm{OC}, \mathrm{H}_{3}\right)\end{array}$ \\
\hline $4 c$ & $\mathrm{C}_{22} \mathrm{H}_{17} \mathrm{O}_{7} \mathrm{~N}_{2} \mathrm{SC}$ & $\begin{array}{l}54.04 \\
(53.95)\end{array}$ & $\begin{array}{l}3.48 \\
(3.35)\end{array}$ & $\begin{array}{l}5.73 \\
(5.65)\end{array}$ & 55 & 135 & $\begin{array}{l}\text { 4.5-4.7 }\left(1 \mathrm{H}, \mathrm{d}, \mathrm{C}_{4} \mathrm{H}\right) \text {, } \\
\text { 5.3-5.4 }\left(1 \mathrm{H}, \mathrm{d}, \mathrm{C}_{3} \mathrm{H}\right) \text {, } \\
\text { 7.2-8.4 (12H,m,aromatic) }\end{array}$ \\
\hline $4 d$ & $\mathrm{C}_{21} \mathrm{H}_{14} \mathrm{O}_{6} \mathrm{~N}_{2} \mathrm{SO}_{2}$ & $\begin{array}{l}51.21 \\
(51.10)\end{array}$ & $\begin{array}{l}2.84 \\
(2.75)\end{array}$ & $\begin{array}{l}5.69 \\
(5.55)\end{array}$ & 50 & 160 & $\begin{array}{l}\text { 4.7-4.8 }\left(1 \mathrm{H}, \mathrm{d}, \mathrm{C}_{4} \mathrm{H}\right) \text {, } \\
\text { 5.3-5.5 }\left(1 \mathrm{H}, \mathrm{d}, \mathrm{C}_{3} \mathrm{H}\right) \text {, } \\
\text { 7.3-8.5 (12H,m,aromatic) }\end{array}$ \\
\hline $4 e$ & $\mathrm{C}_{21} \mathrm{H}_{14} \mathrm{O}_{8} \mathrm{~N}_{3} \mathrm{SC}$ & $\begin{array}{l}50.04 \\
(49.90)\end{array}$ & $\begin{array}{l}2.78 \\
(2.65)\end{array}$ & $\begin{array}{l}8.34 \\
(8.25)\end{array}$ & 45 & 155 & $\begin{array}{l}\text { 4.6-4.8 }\left(1 \mathrm{H}, \mathrm{d}, \mathrm{C}_{\mathrm{C}} \mathrm{H}\right), \\
\text { 5.2-5.3 }\left(1 \mathrm{H}, \mathrm{d}, \mathrm{C}_{3} \mathrm{H}\right) \\
7.3-8.4(12 \mathrm{H}, \mathrm{m}, \text { aromatic }) \\
\text { 3.9 (1H,hump, OH })\end{array}$ \\
\hline $4 f$ & $\mathrm{C}_{21} \mathrm{H}_{15} \mathrm{O}_{7} \mathrm{~N}_{2} \mathrm{SC}$ & $\begin{array}{l}53.10 \\
(52.95)\end{array}$ & $\begin{array}{l}3.16 \\
(3.05)\end{array}$ & $\begin{array}{l}5.90 \\
(5.75)\end{array}$ & 48 & 195 & $\begin{array}{l}\text { 4.6-4.8 }\left(1 \mathrm{H}, \mathrm{d}, \mathrm{C}_{4} \mathrm{H}\right) \text {, } \\
\text { 5.3-5.4 }(1 \mathrm{H}, \mathrm{d}, \mathrm{C} \mathrm{H}) \text {, } \\
\text { 7.2-8.3 }(12 \mathrm{H}, \mathrm{m}, \text { aromatic }) \\
2.9\left(3 \mathrm{H}, \mathrm{s}, \mathrm{OCH} \mathrm{H}_{3}\right),\end{array}$ \\
\hline $4 \mathrm{~g}$ & $\mathrm{C}_{22} \mathrm{H}_{17} \mathrm{O}_{8} \mathrm{~N}_{2} \mathrm{SC}$ & $\begin{array}{l}52.32 \\
(52.20)\end{array}$ & $\begin{array}{l}3.36 \\
(3.25)\end{array}$ & $\begin{array}{l}5.55 \\
(5.45)\end{array}$ & 50 & 170 & $\begin{array}{l}\text { 3.8(1H,hump, } \mathrm{OH}) \text {, } \\
\text { 4.6-4.8 }\left(1 \mathrm{H}, \mathrm{d}, \mathrm{C}_{4} \mathrm{H}\right) \text {, } \\
\text { 5.2-5.3 }\left(1 \mathrm{H}, \mathrm{d}, \mathrm{C}_{3} \mathrm{H}\right) \text {, } \\
\text { 7.2-8.4 (11H,m,aromatic) }\end{array}$ \\
\hline $4 \mathrm{~h}$ & $\mathrm{C}_{23} \mathrm{H}_{19} \mathrm{O}_{8} \mathrm{~N}_{2} \mathrm{SC}$ & $\begin{array}{l}53.23 \\
(53.15)\end{array}$ & $\begin{array}{l}3.66 \\
(3.55)\end{array}$ & $\begin{array}{l}5.40 \\
(5.30)\end{array}$ & 53 & 180 & $\begin{array}{l}3.1\left(6 \mathrm{H}, \mathrm{s}, 2 \mathrm{OCH}_{3}\right) \\
4.6-4.7\left(1 \mathrm{H}, \mathrm{d}, \mathrm{C}_{4} \mathrm{H}\right), \\
5.2-5.3\left(1 \mathrm{H}, \mathrm{d}, \mathrm{C}_{3} \mathrm{H}\right) \text {, } \\
7.2-8.3(11 \mathrm{H}, \mathrm{m}, \text { aromatic })\end{array}$ \\
\hline
\end{tabular}

The above compound (2) on condensation with different aromatic aldehydes in acetic acid yielded different schiff's bases (3a-h). The structures of (3a-h) w ere confirmed, by elemental analysis and the IR spectra showing absorption band at 1640-1620 $(-\mathrm{C}=\mathrm{N})$.

The cyclocondensation reaction of compounds (3a-h) with chloro acetylchloride in dry dioxone in presence of triethylamine (TEA) as catalyst resulted in formation of 2-azetidinones ${ }^{11}$ (4a-h). The structure assigned to (4a-h) were supported by elemental analyses and IR spectra showing absorptions bands at $1750-1740(C=0$ of monocyclic , -lactam). The structures were also confirmed on the basis of ${ }^{1}$ HNMR spectrum.

Acknowledgement

The authors are thankful to Dr. R.M. patel, Head, Department of Chemistry for providing laboratory facilities. 


\section{Reference}

1. Rao J S, Srenivasulu B and Mogilaiah K, Indian J. Chem., 1995, 34B, 734.

2. Kidwai M, Bala R and Kumar K, Indian J. Pharm. Sci., 1995, 57, 252.

3. Hartmann H, Czerney P and Liebscher J, Chem. Asrtr., 1984, 101, 7145.

4. Feng X, Chem R and Lin T, Youji Houxaxue, 1994, 14, 293, Chem. Abstr., 1994, 121, 205276

5. Koppel G A, Small ring Hetrocycles, Wiley Intersciences, New York, 1983.

6. Carke H T, Jhonson J R and Robinson R, The Chemistry of Penicillin, Princeton University Press, Princeton, 1949.

7. Vashi B S, Mehta D S and Shah V H, Indian J. Chem., 1994, 34B, 802.

8. Shepherd R G, Sulfanilamides and other p-amino-benzoic acid antagonists. Medicinal Chemistry, Vol. I, edited by A. Burger, Wiley interscience, Toronto, 1969, 255.

9. Vogel A I, A Textbook of Practical Organic Chemistry, $4^{\text {th }}$ edition, 1978651.

10. Vogel A I, A Textbook of Practical Organic Chemistry, $4^{\text {th }}$ edition, 1978, 652-653.

11. Sharma P, Indapurkar P and Mandloi A, Indian J. Chem, 1998, 37B, 521. 


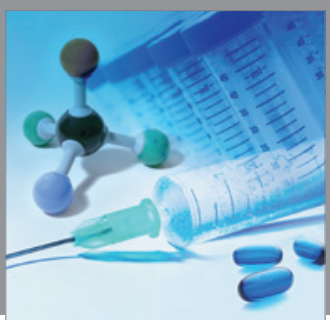

International Journal of

Medicinal Chemistry

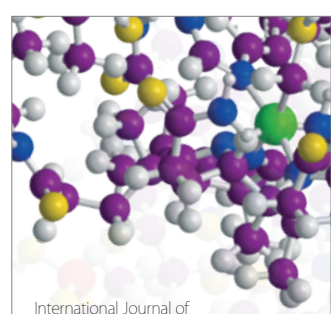

Carbohydrate Chemistry

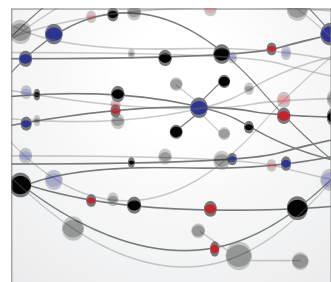

The Scientific World Journal
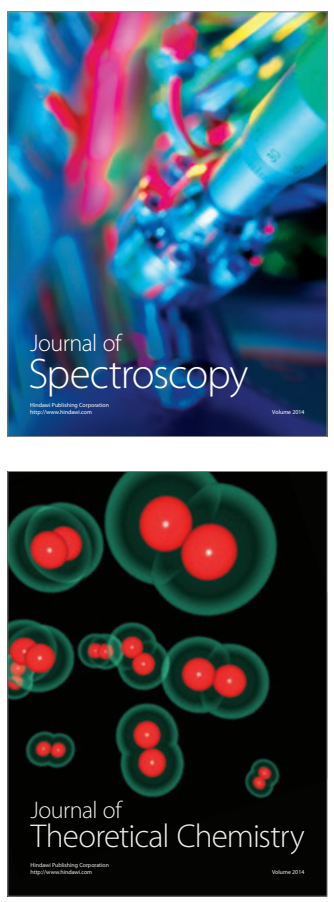
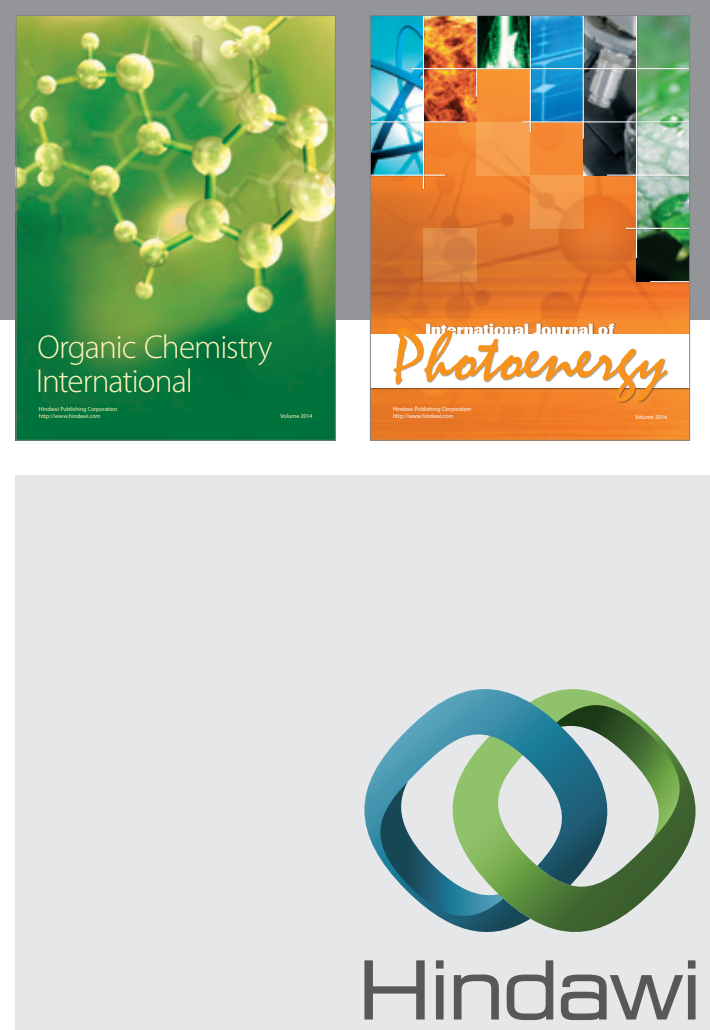

Submit your manuscripts at

http://www.hindawi.com
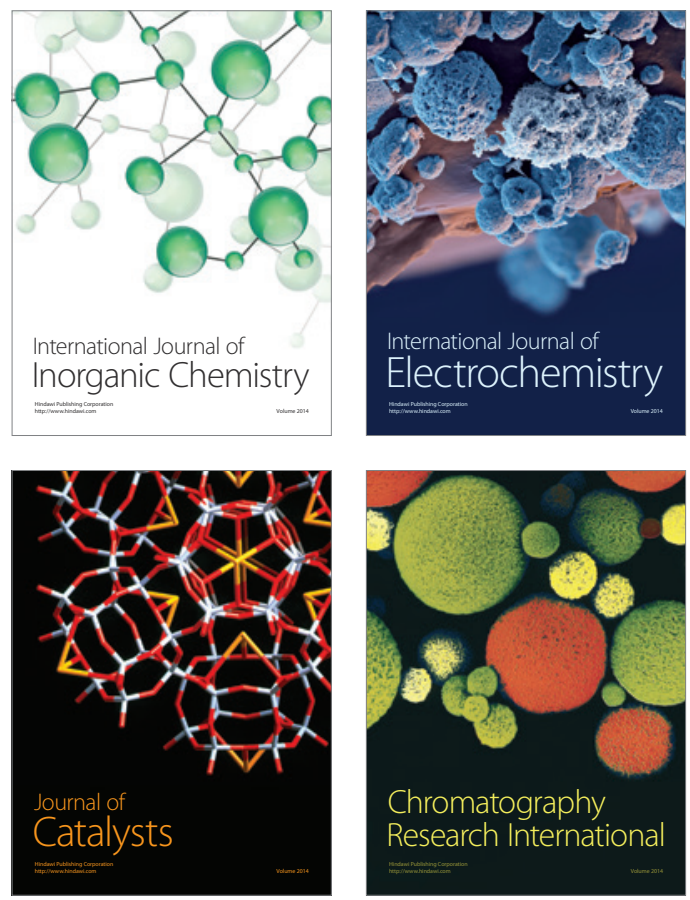
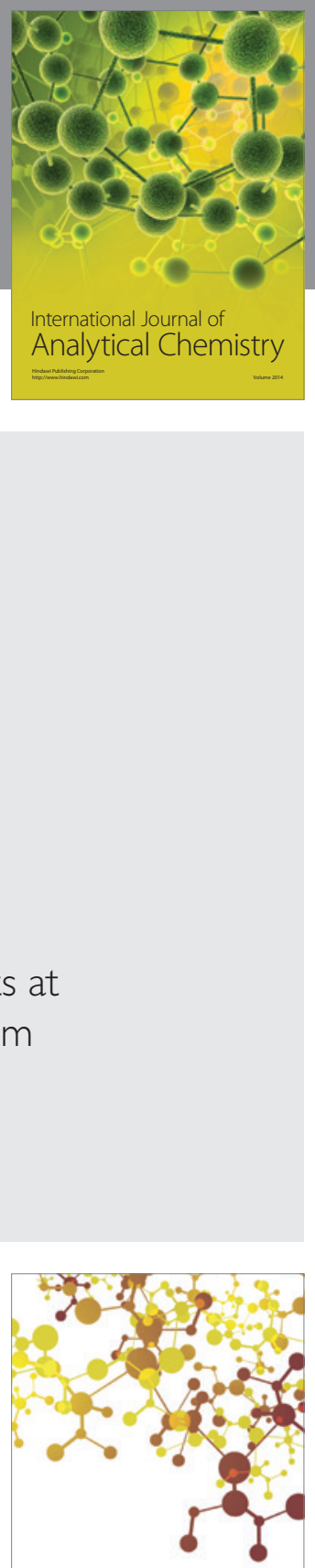

Journal of

Applied Chemistry
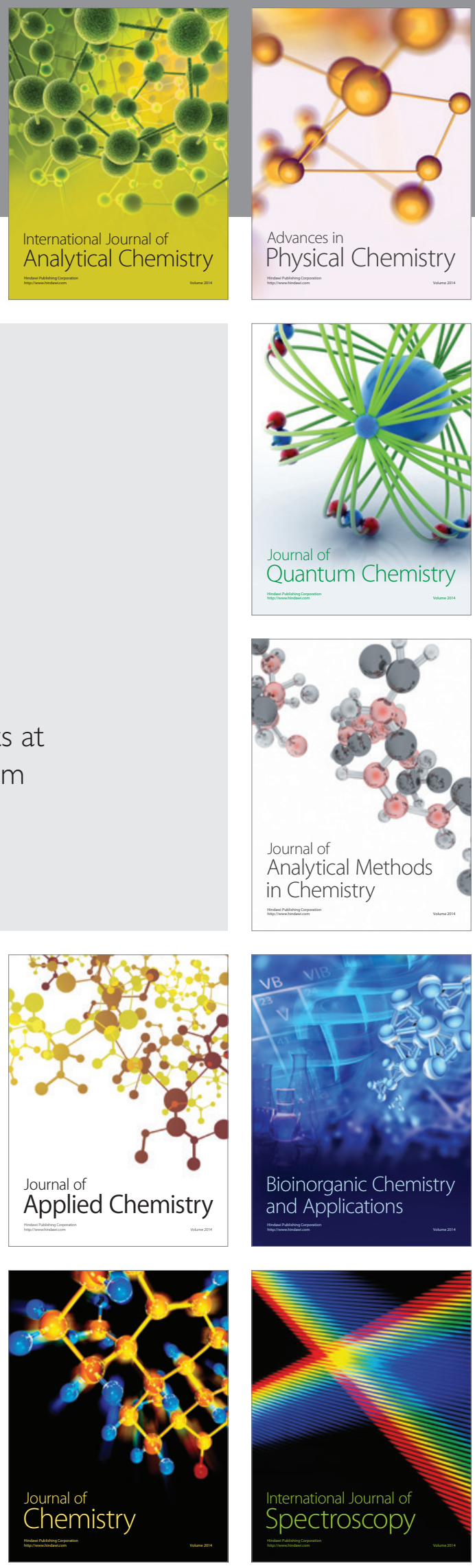